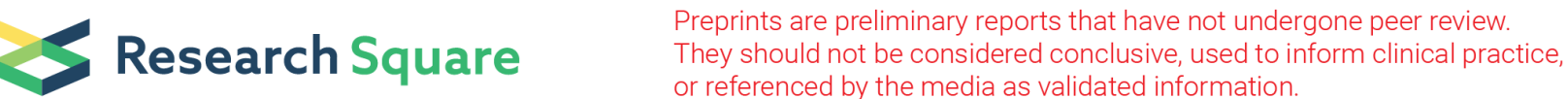

\section{Evaluation of close up antimicrobial therapies for treatment and prevention of subclinical mastitis in the herds with high prevalence of Staphylococcus aureus}

\section{Pooyan Amiri}

Ferdowsi University of Mashhad

Amir Hooshang Fallah Rad

Ferdowsi University of Mashhad

Mohammad Heidarpour

Ferdowsi University of Mashhad

Mohammad Azizzadeh

Ferdowsi University of Mashhad

Babak Khoramian ( $\nabla$ khoramian@um.ac.ir)

Ferdowsi University of Mashhad https://orcid.org/0000-0002-4962-2797

\section{Research article}

Keywords: dry cow therapy, Staphylococcus aureus, subclinical mastitis, close up, antimicrobials

Posted Date: December 6th, 2019

DOI: https://doi.org/10.21203/rs.2.18015/v1

License: (c) (i) This work is licensed under a Creative Commons Attribution 4.0 International License.

Read Full License 


\section{Abstract}

Background: This field trial was conducted to describe and compare the efficacy of two treatment regimens comprising of pre-calving systemic administrations of marbofloxacin and tylosin in combination with dry cow therapy. For more precise detection of Staphylococcus aureus IMI, PCR (nucA gene) and RAPD-PCR genotyping have been applied. A total of 841 quarters from 212 dry cows within two herds were assigned to three groups TYLO, MARB and CONT. At $21 \pm 3$ days prior to parturition, tylosin was injected for three days ( $10 \mathrm{mg} / \mathrm{kg}, \mathrm{SC}$ ) to cows from TYLO and at the same time, single injection of marbofloxacin ( $8 \mathrm{mg} / \mathrm{kg}, \mathrm{SC}$ ) was administered to cows from MARB. Cows assigned to CONT served as an untreated control. All quarters allocated to the groups received intra-mammary infusion of Kanaclox DC ${ }^{\circledR}$ at drying off. Milk samples from all quarters at one week, before last milking of dry off, 3 and 7 DIM were obtained for bacteriological and oxidative analyses.

Results: Despite the fact that no significant differences in total cure rate within the groups was demonstrated, the $S$. aureus cure rate achieved in TYLO and MARB were 74 and $73.5 \%$ respectively both of which being significantly higher than in CONT (58.1\%). No significant differences in total new IMI were observed in TYLO (40.9\%) and MARB (38.5\%) groups compared with CONT group (42.5\%). Furthermore the rate of new S. aureus IMI was higher in TYLO (24.5\%) and MARB (24.1\%) than in CONT (13.8\%) group. Clinical mastitis rate in cows that received systemic injections (TYLO $=3.8 \%, M A R B=5.8 \%$ ) was significantly lower than those detected in control cows (CONT=11.3\%). Paired $\mathrm{S}$. aureus isolates from dry off and post-calving have been clustered into 9 different RAPD types (A-I). 8 paired strains collected at dry off were identical to those at post-calving and 35 strains had more than $60 \%$ of dissimilarity.

Conclusion: The study demonstrates that dealing with herds in which S. aureus IMls are prevalent, using close up broad-spectrum systemic antimicrobial agents can be unrewarding for preventing new $\mathrm{S}$. aureus IMls. However close up administration of systemic antimicrobials have the potential to reduce the incidence of clinical mastitis during lactation.

\section{Background}

The majority cases of mastitis in early lactation are the result of new dry period infections (1). Dry cow therapy (DCT) can reduce the proportion of intra-mammary infections, both by eliminating existing infections and preventing new infections during the dry period (2).

New infection rates are highest in the early dry period, and are lowest when involution is complete, and increase again as parturition approaches (3). During the colostrogenesis stage the protective factors of udder become diluted, the keratin plug breaks down and leukocyte function becomes impaired (4). Administration of antimicrobials in forms of intra-mammary infusion or systemic injection at the beginning of dry off would cover the first half of dry period $(5,6)$. However the level of administered compounds in udder gland will decline to below the MIC (7) resulting in a prophylaxis gap in the close up window $(3,5)$. 
The practice of blanket DCT has been efficient in eliminating existing IMI by 70 to $98 \%$ and provided short-term protection against new IMI during early dry period (reduction by 50 to 75\%) (3). Even though the DCT formulations are labeled effective against gram-positive bacteria they are generally acknowledged as being less successful in eliminating IMI caused by Staphylococcus aureus (8) and new IMI may still occur if offensive pathogens are not susceptible to the antimicrobial preparations. Furthermore the active ingredients of antimicrobial agents do not maintain at therapeutic levels throughout the entire dry period $(5,6)$.

Some reports have been published regarding efficiency of systemic dry cow therapy as management practice (9). Norfloxacin was reported as an effective drug for systemic treatment of $S$. aureus (9). For the same pathogen, Bolourchi et al found that systemic injection of enrofloxacin or tylosin are as efficient as intra-mammary infusion (10). Zecconi reported that administration of tylosin, two weeks before calving, can significantly decrease the IMI rate after calving, compared to those cases treated only at dry off (11).

Based on pharmacokinetic characteristics of macrolides and fluoroqinolones, passage from blood into the udder tissue is rapid and extensive (12). Marbofloxacin as a fluoroqinolone is a broad spectrum antimicrobial and no development of resistance has been found over time to which all the mastitis $S$. aureus isolates were susceptible (13).

Tylosin as a macrolide with basic $\mathrm{pH}$ and lipophilic character can reach milk to plasma concentration ratio of 5:1 (14). This feature would make this antibiotic an ideal parental treatment of IMI.

Genotyping methods have proven a useful tool to determine the diversity and spread of $S$. aureus strains which are not feasible by common bacteriological examination solely. Furthermore using various typing methods, differences regarding pathogenicity and antimicrobial susceptibility have been demonstrated $(15,16)$. Strain-specific characteristics significantly impact the success rate of cure of $S$. aureus $I M I$ after implementing DCT (17).

Sommerhäuser et al, isolated $S$. aureus strains before and after DCT and using genotyping method reported that the actual persistent and newly infected quarters were able to be realized (18). Using RAPDPCR on isolates of $S$. aureus from quarters during acute phase of mastitis and after treatment, it has been revealed that paired isolates were identical and original infective strains persisted $(19,20)$.

The main objective of this study was to describe and compare the effectiveness of two close up protocols of systemic antimicrobial agents in conjunction with routine DCT to cure existing IMI and the prevention of new clinical and subclinical IMI during the dry and early lactation period. Identification of the strains of $S$. aureus through DNA technologies was not commonly incorporated into previous DCT trials, so current study tried to reach a more precise assessment of DCT by taking advantage of a genotyping method.

\section{Results}


At the beginning 900 quarters from 227 cows enrolled at dry off and we excluded cows because of death, abortion, culling and quarters due to contaminated sample. Finally 212 cows representing 841 quarters remained in the study for analysis. TYLO: 291, MARB: 275, CONT: 275 quarters. Mean dry period length of cows included in TYLO, MARB and CONT groups were $57 \pm 3,56 \pm 3$ and $57 \pm 3$ days respectively.

\section{IMls at Dry off and Post-calving}

At dry off, total prevalence of IMIs was $67.8 \%$. In TYLO, MARB and CONT quarters the prevalence was $67.0,60.7$ and $72.4 \%$ respectively which neither of mentioned values was statistically different among all groups $(P>0.05)$. Total prevalence of IMls of post-calving was $61.8 \%$ and within each treatment group was as follows: TYLO $62.2 \%$, MARB $60.4 \%$, CONT $62.9 \%$, which no differences were found within the three groups $(P>0.05)$.

\section{Clinical Mastitis rate}

The proportion of quarters with occurrence of clinical mastitis between dry off and DIM 30 was significantly lower for both treatment groups (TYLO $=3.8 \%, \mathrm{MARB}=5.8 \%)$ vs. CONT $(11.3 \%)$ quarters (figure2).

\section{New Infection rate}

The percent of new IMls acquired by each treatment group regarding every specific pathogen are outlined in Table1. Considering the total pathogens no significant differences were identified for new IMI rates in TYLO (40.9\%), MARB (38.5\%) and CONT (42.5\%) groups $(P>0.05)$. Quarters from TYLO and MARB groups acquired significantly higher new $S$. aureus IMI compared to quarters from CONT group $(P=0.003$, $P=0.004)$.

Factors Affecting New $S$. aureus Infection rate. Among the factors that were analyzed with regression model, the odds of developing a new $S$. aureus IMI were 1.8 and 1.5 times higher for quarters from TYLO $(P<0.05)$ and MARB $(P<0.05)$ respectively. Furthermore, cows with $<30 \mathrm{~kg}$ milk yield $(\mathrm{OR}=5.4, P<0.05)$ and parity of $>2(\mathrm{OR}=2.3, P<0.05)$ had greater odds of developing a new infection. Data summarized in table2.

\section{Cure rate}

The total cure rate was $72.3,76.2$ and $59.6 \%$ for TYLO, MARB and CONT respectively which the differences were not significant among them. The $S$. aureus cure rate achieved with tylosin and marbofloxacin injections was 74 and $73.5 \%$ respectively which both of them were significantly higher than control group (58.1\%). Data of cure rate has been summarized in table3.

Factors Affecting Cure rate. The logistic regression model for cure of quarters is shown in Table4. The odds ratio (OR) of experiencing total cure in quarters that received tylosin and marbofloxacin was 1.3 and 1.4 respectively, which had a tendency to be significant. Quarters infected with CNS that received tylosin 
had greater odds of cure (OD=4.1, $P=0.04)$. Quarters of cows with higher than $30 \mathrm{~kg}$ of daily milk yield less likely to cure compared with those lower than $30 \mathrm{~kg}(P=0.003)$. There was a negative relationship between LS at dry off and likelihood of cure regarding major $(O D=-1.34, P=0.07)$ and minor $(O D=-1.29$, $P=0.04$ ) pathogens.

\section{Disc Agar Susceptibility Test}

Disc agar susceptibility test was performed on $180 \mathrm{~S}$. aureus isolated from dry off and $7 \pm 3 \mathrm{DIM}$. Based on antimicrobial agents used in-vivo, results of 5 antimicrobial discs have been provided in figure3. Generally higher percentages of resistance were found in post-calving isolates compared to dry off isolates. The differences were significant for both tylosin and cloxacillin $(P<0.05)$.

\section{Total Oxidant/Antioxidant Capacity in Quarters with New Infection}

Considering total pathogens, post-calving DTNB[1] concentrations in quarters with new infection were higher than that of in healthy quarters in TYLO $(P<0.01)$, MARB $(P<0.01)$ and CONT $(P<0.05)$ groups. Same results were found for $S$. aureus in TYLO $(P<0.01)$, MARB $(P<0.01)$ and CONT $(P<0.01)$ groups. FRAP[2] concentrations were higher in cured quarters compared to uncured quarters in TYLO $(P<0.01)$, MARB $(P<0.05)$ and CONT $(P<0.01)$ groups. Furthermore FRAP concentrations had a tendency to impact 1.3 times on odds of experiencing cure $(P=0.09)$. Data have been summarized in table5.

\section{RAPD[3]-PCR}

The RAPD-PCR technique was shown to be efficient in typing the studied strains. Out of the two primers used, Ap4 showed a better discriminatory power than T3. Amplification of the AP4 primer resulted in a multiple amplicon with size range from $100 \mathrm{bp}$ to more than $2000 \mathrm{bp}$ from all of $86 \mathrm{~S}$. aureus isolates. The $43 \mathrm{~S}$. aureus paired samples selected from quarters that were infected before (dry off) and after parturition $(7 \pm 3 D I M)$. Isolates were characterized into 9 different RAPD types $(A-I)$ with instead of which the majority of isolates being categorized as A, B, E and G type. 8 paired strains collected at dry off stage were identical to those collected at post-calving and 35 strains from dry off had more than $60 \%$ of dissimilarity to post-calving strains. RAPD patterns for isolates in this study have been provided as a dendrogram in figure4. Different patterns of antimicrobial resistance among four predominant RAPD types $(A, B, E, G)$ in each herd have been given in table6. Penicillin resistance in type $E$ was lower compared to other types in both herds and tylosin resistance in type $G$ was lower than other types in both herds. Penicillin and tylosin resistance in type $E$ from herd 1 were considerably higher than same type from herd2.

[1] (5,5'-Dithiobis(2-nitrobenzoic acid)

[2] Ferric Reducing Ability of Plasma 
[3] Random Amplification of Polymorphic DNA

\section{Discussion}

The object of this study was to evaluate the efficacy of systemic antimicrobial agents at close-up period for treatment of existing infections that had not been cured by dry off intra-mammary preparations and the control of new IMI with emphasize on S.aureus strains.

\section{Clinical Mastitis rate}

In the present study pre-calving systemic injection of tylosin and marbofloxacin effectively reduced the occurrence of clinical mastitis within 30 days of calving. Although there is no study on the effect of close up systemic antimicrobial agents on incidence of clinical mastitis, some studies had previously compared effects of blanket or selective DCT. Ismail et al. evaluated the effect of systemic $12 \mathrm{~g}$ of tylosin in conjunction with intra-mammary infusion of beta lactam antibiotics and framycetin. These authors stated that the rate of clinical mastitis within the 100 DIM was significantly reduced in cows received tylosin (21). Contradictory results have been reported from Australia indicating more clinical mastitis rate after DCT (6). Pathogen isolation was not performed for clinical cases in this study but based on previous studies it is presumed that the most of clinical mastitis cases are caused by environmental pathogens including streptococci and coliform bacteria (22). Tylosin as member of Macrolides have high MIC for gram-negative bacteria (23) and generally is effective against gram positive bacteria. In case of our study the high doses of the drug $(20 \mathrm{mg} / \mathrm{kg})$ was administered for three consecutive days. On the other hand marbofloxacin has a wide spectrum of activity and it has been proven that Escherichia coli strains are very susceptible to marbofloxacin with a very low MIC90 (24). Bradley et al. demonstrated that using an antimicrobial agent with a gram negative spectrum as DCT can influence the incidence of clinical coliform mastitis in the subsequent lactation (5). The findings of present study and other related studies confirm that dry cow therapy can play a role in the clinical mastitis epidemiology in early lactation. In respect to lack of DC intra-mammary products specific to gram negative bacteria in the market, it might be beneficial to take advantage of potent systemic antimicrobial agents with proper effectiveness on gram negative bacteria.

\section{New Infection rate}

Based on our data regarding total pathogens, systemic therapy with tylosin or marbofloxacin prior to parturition did not significantly decrease the total rate of new infection. Furthermore the rate of new infection by $S$. aureus was higher in quarters which received tylosin or marbofloxacin. Unlike to the present study which the adjunct systemic antimicrobials were administered three weeks before calving, in the most of previous studies the systemic antimicrobial agents had been administered at the beginning of drying off which made the comparison difficult. Contreras et al, used $12 \mathrm{~g}$ of systemic tylosin combined with intra-mammary infusion and teat seal to prevent new infection and it was established that addition of systemic tylosin was not effective (25). Lower rate of new IMI in that study might be because of lower prevalence of S. aureus (4.5\%) compared to our study (15.1\%) and taking the advantage of teat seal 
which was not used in present study. in both herds of under present investigation $S$. aureus was prevalent and it has been noted that contagious bacteria, especially $S$. aureus, are likely to establish more new infections in those herds where they are prevalent (26).

The findings from Erskine et al. suggested that intra-mammary infusion of cephapirin benzathine combined with four consecutive days of oxytetracycline injections were no more effective than intramammary infusion alone in preventing infection (27). In contrast to our study findings, Soback et al. reported significantly fewer $S$. aureus new IMIs occurrence in both systemic norfloxacin and oxytetracycline groups than in the group receiving intramammary infusion of cephapirin and the control group. It should be noted that in that study the systemic treatments were not used concurrently with intramammary infusion instead, they were administered at the onset of dry period. Another study revealed that combination of a high persistency product and pre-partum treatment with a lactating cow product did not significantly reduce the number of $S$. aureus infections postpartum when compared with intra-mammary infusion alone (28).

One explanation for the relatively poor preventive success of pre-calving systemic antimicrobial agents against $S$. aureus IMI in the present study might be related to the higher cure rate of CNS and $C$. bovis infections in treatment groups compared to control. Several authors stated that CNS bacteria can protect quarters against IMI caused by major pathogens, either when causing IMI $(29,30)$ or when colonizing bovine teats (31). Data from Pankey and Nickerson suggest that quarters containing $C$. bovis are more resistant to $S$. aureus infections (32). It is possible that elimination of minor pathogens by systemic antimicrobial agents has increased the susceptibility of treated quarters and higher percentages of CNS and $C$. bovis in the control quarters had protective effects against $S$. aureus. General activation of the immune system, competition for binding sites and alterations in teat canal keratin are suggested as possible explanations (33).

Another explanation could be the development of resistance to antimicrobial agents. S. aureus isolates typical of present IMI cannot be directly compared with those identified of 20 to 30 years ago. Additionally according to in-vitro susceptibility data, post-calving and dry off $S$. aureus isolates showed notable resistance behaviors against the antimicrobial agents used.

RAPD-PCR fingerprint types from post-calving isolates were mostly different from those isolated at dry off. It is noteworthy that all of 4 main RAPD types were resistant against penicillin. A and B types were more resistant to tylosin and marbofloxacin than E and $\mathrm{G}$ types (table9). Dingwell et al. indicated that certain genotypes of $S$. aureus show different responses to systemic antimicrobial agents during dry period (17).

Factors Affecting New Infection rate. We saw increased proportion of new IMI in cows with higher than two parities. A similar association between the risk of acquiring IMI in dry period and parity has been previously documented (34). Increased IMI associated with higher parity might be related to a decrease in the integrity of the streak canal (35). 


\section{Cure rate}

Generally the cure rates for infected quarters in different groups are similar to those reported in previous studies with the calculated average of $78 \%$ (71 to $85 \%$ ) (36). The S. aureus cure rate for quarters received intra-mammary infusion solely is similar to those reported in initial drug efficacy studies (36). We observed that the total cure rate after pre-calving injections of tylosin or marbofloxacin alongside with intra-mammary infusion compound were not significantly different compared to intra-mammary infusion alone. Similarly in a study by Erskine et al. cows administered intramuscular oxytetracycline and intramammary cephapirin and the cure rates of quarters did not improved compared to quarters treated with cephapirin alone (27). Bolourchi et al., found that systemic enrofloxacin or tylosin at drying off approached but did not increase the efficacy of intra-mammary infusion (10). The aforementioned studies were performed in herds with high prevalence of $S$. aureus. We observed that both tylosin and marbofloxacin improved $S$. aureus cure rate which is consistent with results from another study in which systemic norfloxacin was administered at the start of the dry period that achieved a better $S$. aureus cure rate compared to intramammary cephapirin (37). Zecconi et al., reported that administration of systemic tylosin 2 weeks before calving, alongside with traditional dry-cow therapy is an effective supplementary treatment for intra mammary therapy of $S$. aureus (11).

Strain-specific characteristics can be expected to affect the probability of cure of Staph. aureus IMI, but we did not detect strain-specific response in RAPD types. Dingwell et al. observed a strain-specific response to tilmicosin or cloxacillin as dry cow treatment and reported that the three predominant groups of strains, responded well to tilmicosin compared to the rest of groups (34). More studies are warranted to examine the variability of treatment responses in different strains of $S$. aureus. Moreover, high proportion of strains isolated in present study were resistant to penicillin. It has been found that the probability of cure is lower for penicillin-resistant $S$. aureus than for penicillin-susceptible strains (38).

Factors Affecting Cure rate. The Odds of cure was lower in quarters with higher than $30 \mathrm{~kg}$ of daily milk yield. Higher milk production is usually associated with larger mammary gland size while the antimicrobial agent must diffuse through a larger tissue and a larger amount of tissue needs be cleared of infection (38). Probability of cure for total and specific pathogens tended to reduce with LS enhancement. Similarly, others observed that the probability of cure in quarters infected with $S$. aureus decreased as SCC increased $(17,39)$. High cow-level SCC may also indicate that multiple quarters within the udder are infected which more infected quarters means less chance of cure (8).

\section{Antimicrobial Susceptibility Test}

In the present study rather than penicillin and cloxacillin resistance considerable percentage of isolates were resistant to tylosin particularly in isolates from post-calving samples .Both phenotypic (40) and genotypic (41) tylosin resistance in $S$. aureus isolates have been reported from subclinical mastitis cases in Iran. Extraordinary usage of macrolides for treatment of mastitis in Iranian dairy farms in recent years might be as a one of underlying causes. Because of elimination of susceptible strains by dry off 
treatment and introducing some new strains, there were some discrepancies in resistance character of strains from dry off and post-calving.

\section{RAPD-PCR}

Based on results of RAPD-PCR, in quarters in which $S$. aureus was isolated in both dry off and postcalving, dry-off strains were not persisted in the udder and reinfection has been made by different $S$. aureus strains. Contradictory result has been reported by Myllys et al. who stated that $S$. aureus strains have been persisted in udder without reinfection by other strains (19). These authors implemented ribotyping as well which was not used in our study. Moreover in that study the poor cure rates of S.aureus were associated to persistence of the original strain. Four predominant RAPD types $(A, B, E, G)$ were detected in present study. Based on genotyping survey by Sommerhäuser et al., in some herds one type of strains are dominant while in some herds multiple dominant types exist (18). The later scenario was found in both herds of present study.

\section{Milk Oxidant and Antioxidant Capacity}

In recent years, free radical damage has become increasingly important as a complementary tool in the evaluation of inflammatory status. It was not an objective of this study to describe the mechanism but we have investigated possible connection of oxidant/anti-oxidant markers to the new infected, cured quarters or even as a related risk factor.

Generally post-calving total oxidant capacity (TOC) (DTNB) in quarters with new infection was higher than that of in healthy quarters which is consistent with results of study by Atakisi et al., who reported that TOC levels were significantly higher in milk of glands with subclinical mastitis compared to normal glands (42). In another study performed on goat the authors sustained the similar results (43). Infection of mammary gland causing expansion in the number of neutrophils, epithelial cells and cytokines in mammary tissue which resulted in enhancement of free radicals in milk (44).

According to data from regression analysis, TAC tended to impact 1.3 times on odds of cure. Probably the quarters with higher antioxidant capacity have more potency to overcome infections. Future studies are needed to determine the effects of various blood and milk oxidant/antioxidants markers on probability of cure and acquiring new infection.

\section{Conclusion}

The results generated in present study suggest that close up systemic administration of tylosin or marbofloxacin resulted in reduction of post-calving clinical mastitis rate but were not able to prevent new IMIs. Considering the probability of eliminating minor pathogens without affecting the major pathogens, this protocol appeared to be unsatisfactory for prevention of new IMIs in herds with high prevalence of $S$. aureus. Conducting antimicrobial susceptibility test, molecular typing for isolated pathogens and 
assessment of oxidant/antioxidant capacity of milk could be a valuable tool for selecting appropriate therapeutic compounds as a part of dry cow management.

\section{Methods}

\section{Cow/ herd Selection and Sampling}

Two commercial free-stall Holstein dairy herds with high bulk milk count of $S$. aureus (ranged from 50 to $60 \mathrm{CFU} / \mathrm{mL}$ ), milking 800 (herd 1) and 300 (herd 2) cows were selected for this study. Daily milk yield were 38 and $40 \mathrm{~L}$ respectively. Cows eligible for study had to be in fine health with functional quarters free of clinical mastitis and notable teat lesions without receiving antimicrobial or anti-inflammatory agents within the last two weeks. The cows were dried off by gradual cessation of milking at $60 \pm 3$ days prior to expected date of calving. Three foremilk samples from each quarter aseptically collected one week before and at the last milking of drying off and immediately transferred to the laboratory in a styrofoam box containing ice. Following the last milking, all quarters were disinfected and infused with Kanaclox DC ${ }^{\circledR}$ (Pars Dopharma, Iran); Kanamycin acid sulfate $100000 \mathrm{IU}$, Cloxacillin Benzathine $500 \mathrm{mg}$, Penicillin G Procaine 300000 IU and Oilbase: $10 \mathrm{gr}$ ). Post-calving milk samples were taken at 3 and 7 DIM.

\section{Study Design}

Following DCT cows were randomly allocated to one of the three groups (TYLO, MARB and CONT) via block randomization. Cows in TYLO received once daily SC injection of $10 \mathrm{mg} / \mathrm{kg} \mathrm{mg}$ tylosin (Tyloject ${ }^{\circledR}$ $20 \%$, Razak Laboratories Co, Iran) for three days, at $21 \pm 3$ days prior to calving and cows in MARB received single SC injection of $8 \mathrm{mg} / \mathrm{kg}$ SC marbofloxacin (Marbox ${ }^{\circledR}$, Ceva Santé Animale BV, Netherlands) at $21 \pm 3$ days prior to calving while cows assigned to CONT remained untreated (Figure1).

\section{Milk Sample Analysis}

Somatic Cell Counts. Composite milk samples from last month before dry off were counted by electric counter (Fossomatic Milk Analysis, Foss Electric, Hillerød, Denmark) and linear score (LS) was calculated subsequently.

Laboratory Bacteriological Culture. Culture techniques and identification of bacteria were performed according to instructions from National Mastitis Council (45). Diagnosis of various pathogens was made based on morphology, growth on selective and differential media, Gram staining, hemolysis, catalase, MSA, hippurate and CAMP. A sample was considered contaminated if more than 3 bacterial species were present on a plate.

Identification of S.aureus Isolates. The isolates were submitted to VP (Voges Proskauer) and coagulase tests. The quarters considered to be infected if $>100 \mathrm{CFU} / \mathrm{ml}$ of $S$. aureus isolated from each cultures of 
any one milk sample taken at dry off and post-calving. To confirm the identification of isolates as $S$. aureus, the gene was amplified by nucA via conventional PCR method.

Antimicrobial Susceptibility Test. The Agar disk diffusion method (ADD) was used to determine the susceptibility of $S$. aureus isolates. Procedures were based on the Clinical and Laboratory Standards Institute (CLSI) guidelines (46). S. aureus ATCC 29213 was used as the reference strain for quality control.

nUCA PCR. DNA extraction was performed by rapid boiling according to method by Abdelhai et al.(47). Primers were selected on the basis of the published nucleotide sequence of the 613-bp nuc gene (F- CTG GCA TAT GTA TGG CAA TTG TT, R- TAT TGA CCT GAA TCA GCG TTG TCT).

RAPD-PCR. In quarters from which $S$. aureus was isolated from both dry off and post calving, the genomic variability of the $S$. aureus isolations was analyzed by RAPD-PCR method based on two primer AP4(5' TCACGCTGCA 3') and T3 (5'ATTAACCCTCACTAAAGG3'). The amplification conditions for AP4 primer performed based on study by Morandi et al. (48). Amplification cycle of the T3 primer has been described by Pinto et al. (49). Thermal cycler (BIO RAD ${ }^{\circledR}$, USA).

Amplification products were electrophoresed on a 1.8\% agarose gel (Bio-Rad, California, USA) in TAE buffer. Gels were stained with ethidium bromide and photographed under UV light. PCR fingerprint images were analyzed estimated band sizes using Gel Compar ${ }^{\circledR} \|$ (Applied Maths, Inc, Austin, USA) software. Strains were clustered and displayed in dendrogram form with consideration of $60 \%$ genetic similarity.

\section{Biochemical Analysis}

Total Antioxidant Capacity (TAC). Antioxidant capacity of skim milk samples was assessed by the method of FRAP(50). The reduction of Fe3+-TPTZ to Fe2+-TPTZ was followed by the absorbance increase at $595 \mathrm{~nm}$ via spectrophometer $\left(2150-\mathrm{UV}, \mathrm{UNICO}^{\circledR}, \mathrm{USA}\right)$.

Total Oxidant Capacity (TOC). Oxidant capacity of skim milk samples was analyzed by measuring DTNB based on the method applied by (43). The decrease in absorbance at $412 \mathrm{~nm}$ was used to calculate the rate of oxidation of TNB to DTNB. The parameters have measured in each sample three times and coefficient of variation (CV) was calculated by the formula (SD/mean $\times 100)$. Within-run CV were $<1.0 \%$ at all values tested. Between-series imprecision and bias have been evaluated as well.

The investigator of the tests was blinded to group allocation.

\section{Statistical Analysis}

In general, the statistical analysis was performed using SPSS software (version 21.0; SPSS Inc., Chicago, USA). The sample size calculated based on confidence level of $95 \%$ and power of $90 \%$. Chi-square analysis was used to investigate the differences in cure, new infection and clinical mastitis rates among 
treatment groups. Logistic regression was carried out to determine the effect of treatments on the probability of cure, new infection and clinical mastitis controlling for parity, milk yield, position of quarter and oxidant/antioxidant balance at dry period. Kaplan-Meier survival curves were plotted to show survival distribution function of quarters with clinical mastitis for each level of treatments. Mann-Whitney $U$ test was used for comparison of DTNB and FRAP between cured and uncured and new infected and healthy quarters. All statistical differences were assessed at the two-sided 0.05 level of significance.

\section{Definition of Dependent Variables}

Developing New Infection Between Dry off and 7 \pm 3 DIM. A new IMI was defined as the presence of pathogen at 3 or 7 DIM in a quarter that was not previously infected at dry off, or the presence of a different pathogen from those present at dry off (51). In cases of mixed infections, a quarter was counted only once as having a new IMI, even if 2 new bacterial pathogens were cultured. In the cases which RAPDPCR revealed an $S$. aureus isolate at calving belonged to different strain than $S$. aureus isolate at dry off, they were considered to new IMI.

Developing Clinical Mastitis. A clinical mastitis occurrence was defined as the appearance of obvious abnormal milk (with/without abnormal mammary gland or systemic signs of illness). A quarter developing one or more episodes of clinical mastitis between dry off and 30 \pm 3 DIM was classified as a positive clinical mastitis case.

Experiencing Cure. Cure was defined as the elimination of one or more pathogens at both 3 and 7 DIM that previously had been existed at dry off. The RAPD-PCR results were considered for the calculation of cure rate regarding the quarters which $S$. aureus isolated from both dry off and post-calving.

\section{Abbreviations}

DIM: days in milk

IMI: Intra-mammary infection

MIC: Minimum inhibitory concentration

\section{Declarations}

\section{Ethics approval and consent to participate}

The present study included cows. Protocol of study was confirmed by animal welfare committee of Ferdowsi University of Mashhad (38059) in accordance with institutional and national and/or international guidelines.

\section{Consent for publication}

Not applicable 


\section{Availability of data and materials}

The datasets used and/or analyzed during the current study are available from the corresponding author on reasonable request.

\section{Competing interests}

The authors declare that they have no competing interests

\section{Funding}

The financial sources were supported by Ferdowsi University of Mashhad (Grant No. 3/38059).

\section{Authors' contributions}

Research concept and design: BK, AHFR; Statistical analysis: MA; Samples collection: PA;

LAB Tests: MH, BK; Experiment performance: PA; Manuscript writing: PA, BK; All the

authors read and approved the final manuscript.

\section{Acknowledgment}

The authors acknowledge the contribution of herd staff: Dr. M Aynechian and Dr. M Haddadi. Also the support of Dr. H Kalaterahmani and Dr. N Ameri is fully appreciated

\section{References}

1. Eberhart R, Buckalew J. Intramammary infections in a dairy herd with a low incidence of Streptococcus agalactiae and Staphylococcus aureus infections. J Am Vet Med. Assoc. 1977;171(7):630-4.

2. Neave F, Dodd F, Henriques E. 408. Udder infections in the 'dry period'. J DairyRes. 1950;17(1):37-49.

3. Smith KL, Todhunter D, Schoenberger P. Environmental Pathogens and Intramammary Infection During the Dry Period. J DairySci. 1985;68(2):402-17.

4. Bradley AJ, Green MJ. The importance of the nonlactating period in the epidemiology of intramammary infection and strategies for prevention. Vet Clin North Am FoodAnim Pract. 2004;20(3):547-68.

5. Bradley A, Green M. An investigation of the impact of intramammary antibiotic dry cow therapy on clinical coliform mastitis. J DairySci. 2001;84(7):1632-9.

6. Browning J, Mein G, Barton M, Nicholls T, Brightling P. Effects of antibiotic therapy at drying off on mastitis in the dry period and early lactation. Aust Ve J. 1990;67(12):440-2.

7. Oliver S, Maki J. Persistence of antibiotic residues in mammary secretions during the nonlactating period following intramammary infusion at drying off. J Dairy Sci. 1987;70(Suppl 1):163. 
8. Østerås $\mathrm{O}$, Edge V, Martin S. Determinants of success or failure in the elimination of major mastitis pathogens in selective dry cow therapy. J DairySci. 1999;82(6):1221-31.

9. Soback S, Ziv G, Winkler M, Saran A. Systemic dry cow therapy-a preliminary report. J DairySci. 1990;73(3):661-6.

10. Bolourchi M, Hovareshti P, Tabatabayi A. Comparison of the effects of local and systemic dry cow therapy for staphylococcal mastitis control. Prev Vet Med. 1995;25(1):63-7.

11. Zecconi A, Piccinini R, Guarini C. Efficacy of tylosin in cows during dry-off period [for prevention and treatment of intramammary infections]. O\&DV Obiettivi e Documenti Veterinari (Italy). 1999.

12. Ziv G. Practical pharmokinetic aspects of mastitis therapy. I. Parenteral treatment.Vet Med SmallAnim Clin. 1980;75(2):277-90.

13. Meunier Dd, Acar J-F, Martel J-L, Kroemer S, Valle M. Seven years survey of susceptibility to marbofloxacin of bovine pathogenic strains from eight European countries. Int J Antimicrob Agents. 2004;24(3):268-78.

14. Riviere JE. Comparative pharmacokinetics: principles, techniques and applications: John Wiley \& Sons; 2011.

15. Haveri M, Taponen S, Vuopio-Varkila J, Salmenlinna S, Pyörälä S. Bacterial genotype affects the manifestation and persistence of bovine Staphylococcus aureus intramammary infection. J Clin Microbiol. 2005;43(2):959-61.

16. Fitzgerald J, Hartigan P, Meaney W, Smyth C. Molecular population and virulence factor analysis of Staphylococcus aureus from bovine intramammary infection. J Appl Microbiol. 2000;88(6):1028-37.

17. Dingwell RT, Leslie KE, Sabour P, Lepp D, Pacan J. Influence of the genotype of Staphylococcus aureus, determined by pulsed-field gel electrophoresis, on dry-period elimination of subclinical mastitis in Canadian dairy herds. Can J Vet Res .2006;70(2):115.

18. Sommerhäuser J, Kloppert B, Wolter W, Zschöck M, Sobiraj A, Failing K. The epidemiology of Staphylococcus aureus infections from subclinical mastitis in dairy cows during a control programme. Vet Microbiol. 2003;96(1):91-102.

19. Myllys V, Ridell J, Björkroth J, Biese I, Pyörälä S. Persistence in bovine mastitis of Staphylococcus aureus clones as assessed by random amplified polymorphic DNA analysis, ribotyping and biotyping. Vet Microbiol. 1997;57(2-3):245-51.

20. Lipman LJ, de Nijs A, Lam TJ, Rost JA, van Dijk L, Schukken YH, et al. Genotyping by PCR, of Staphylococcus aureus strains, isolated from mammary glands of cows. Vet Microbiol. 1996;48(12):51-5.

21. Ismail ZB, Muhaffel MM, Abu-Basha E. The effect of dry cow therapy using systemic tylosin in combination with common intramammary medications on mastitis rate, cull rate, somatic cell count, and milk production in dairy cows affected with subclinical mastitis. Vet World. 2018;11(9):1266.

22. Bradley AJ. Bovine mastitis: an evolving disease. Vet J. 2002;164(2):116-28. 
23. Salmon S, Watts J, Aarestrup FM, Pankey J, Yancey R. Minimum inhibitory concentrations for selected antimicrobial agents against organisms isolated from the mammary glands of dairy heifers in New Zealand and Denmark. J DairySci. 1998;81(2):570-8.

24. Schneider M, Valle M, Woehrle F, Boisrame B. Pharmacokinetics of marbofloxacin in lactating cows after repeated intramuscular administrations and pharmacodynamics against mastitis isolated strains. J DairySci. 2004;87(1):202-11.

25. Contreras B, Andres G, Guterbock WM, Muñoz R, Sears PM. Comparison of systemic and intramammary dry cow treatments. Rev MVZCordoba. 2013;18(1):3259-64.

26. Berry E, Hillerton J. The effect of selective dry cow treatment on new intramammary infections. J DairySci. 2002;85(1):112-21.

27. Erskine R, Bartlett P, Crawshaw P, Gombas D. Efficacy of intramuscular oxytetracycline as a dry cow treatment for Staphylococcus aureus mastitis. J DairySci. 1994;77(11):3347-53.

28. Pankey J, Barker R, Twomey A, Duirs G. Comparative efficacy of dry-cow treatment regimens against Staphylococcus aureus. N Z Vet J. 1982;30(1-2):13-5.

29. Lam T, Schukken $Y$, Grommers $F$, Tielen M, Brand A. Effect of natural infection with minor pathogens on susceptibility to natural infection with major pathogens in the bovine mammary gland. Am $\mathrm{J}$ Vet Res. 1997;58(1):17-22.

30. Matthews K, Harmon R, Langlois B. Prevalence of Staphylococcus species during the periparturient period in primiparous and multiparous cows. J DairySci. 1992;75(7):1835-9.

31. De Vliegher S, Opsomer G, Vanrolleghem A, Devriese L, Sampimon O, Sol J, et al. In vitro growth inhibition of major mastitis pathogens by Staphylococcus chromogenes originating from teat apices of dairy heifers. Vet Microbiol. 2004;101(3):215-21.

32. Pankey J, Nickerson S, Boddie R, Hogan JS. Effects of Corynebacterium bovis infection on susceptibility to major mastitis pathogens. J DairySci. 1985;68(10):2684-93.

33. Nickerson S, Boddie R. Effect of Naturally Occurring Coagulase-Negative Staphylococcal Infections on Experimental Challenge with Major Mastitis Pathogens. J DairySci. 1994;77(9):2526-36.

34. Dingwell R, Leslie K, Schukken Y, Sargeant J, Timms L, Duffield T, et al. Association of cow and quarter-level factors at drying-off with new intramammary infections during the dry period. Prev Vet Med. 2004;63(1-2):75-89.

35. Cousins CL, Higgs TM, Jackson ER, Neave FK, Dodd FH. Susceptibility of the bovine udder to bacterial infection in the dry period. J DairyRes. 1980;47(1):11-8.

36. Halasa T, Nielen $M$, Whist AC, Østerås 0 . Meta-analysis of dry cow management for dairy cattle. Part 2. Cure of existing intramammary infections. J DairySci. 2009;92(7):3150-7.

37. Soback S, Adler H, Van Damm B, Winkler M, Ziv G, Saran A, editors. Systemic dry cow therapy in control of subclinical Staphylococcus aureus infections. Proceedings of the International Symposium on Bovine Mastitis, Indianapolis, IN; 1990: National Mastitis Council Madison (WI). 
38. Barkema H, Schukken Y, Zadoks R. Invited review: The role of cow, pathogen, and treatment regimen in the therapeutic success of bovine Staphylococcus aureus mastitis. J DairySci. 2006;89(6):187795.

39. Sol J, Sampimon O, Snoep J, Schukken Y. Factors associated with bacteriological cure after dry cow treatment of subclinical staphylococcal mastitis with antibiotics. J DairySci. 1994;77(1):75-9.

40. Pourtaghi H, Azizi AG, Sodagari H. Antimicrobial resistance patterns of Staphylococcus aureus isolated from bovine subclinical mastitis in Alborz province, Iran. Bulg J Vet Med. 2016;19(2):169-74.

41. Bahraminia F, Emadi SR, Emaneini M, Farzaneh N, Rad M, Khoramian B, editors. A high prevalence of tylosin resistance among Staphylococcus aureus strains isolated from bovine mastitis. Vet Res Forum. 2017;18(2):1345-85.

42. Atakisi O, Oral H, Atakisi E, Merhan O, Pancarci SM, Ozcan A, et al. Subclinical mastitis causes alterations in nitric oxide, total oxidant and antioxidant capacity in cow milk. Res Vet Sci. 2010;89(1):10-3.

43. Silanikove N, Merin U, Shapiro F, Leitner G. Subclinical mastitis in goats is associated with upregulation of nitric oxide-derived oxidative stress that causes reduction of milk antioxidative properties and impairment of its quality. J. DairySci. 2014;97(6):3449-55.

44. Sadek K, Saleh E, Ayoub M. Selective, reliable blood and milk bio-markers for diagnosing clinical and subclinical bovine mastitis. Trop Anim HealthProd. 2017;49(2):431-7.

45. Council NM. Laboratory handbook on bovine mastitis: NMC; 2005.

46. Wayne P. Clinical and laboratory standards institute. Performance standards for antimicrobial susceptibility testing. 2011.

47. Abdelhai MH, Hassanin HA, Sun X. Comparative study of rapid DNA extraction methods of pathogenic bacteria. Am J Biosci Bioeng. 2016;4:1-8.

48. Morandi S, Brasca M, Lodi R, Brusetti L, Andrighetto C, Lombardi A. Biochemical profiles, restriction fragment length polymorphism (RFLP), random amplified polymorphic DNA (RAPD) and multilocus variable number tandem repeat analysis (MLVA) for typing Staphylococcus aureus isolated from dairy products. Res. Vet. Sci. 2010;88(3):427-35.

49. Pinto B, Chenoll E, Aznar R. Identification and typing of food-borne Staphylococcus aureus by PCRbased techniques. Syst Appl Microbiol. 2005;28(4):340-52.

50. Chen J, Lindmark-Månsson H, Gorton L, Åkesson B. Antioxidant capacity of bovine milk as assayed by spectrophotometric and amperometric methods. Int DairyJ. 2003;13(12):927-35.

51. Huxley J, Green M, Green L, Bradley A. Evaluation of the efficacy of an internal teat sealer during the dry period. J DairySci. 2002;85(3):551-61. 


\section{Tables}

Table1: Results of total and pathogen specific new IMI rate considering uninfected quarters and quarters infected by different pathogen between dry off and 7 \pm 3 DIM.

\begin{tabular}{cccccccccc}
\hline group & Total \%(n) & S.aureus & CNS & C. bovis & S.agalactiae & Yeast & Other & Minor & Major \\
\hline TYLO & 40.9 & a 24.5 & 24.8 & 6.5 & 0.0 & 0.0 & 0.3 & 29.3 & a 25.5 \\
& $(119 / 291)$ & $(59 / 241)$ & $(49 / 197)$ & $(17 / 261)$ & $(3 / 287)$ & $(0 / 290)$ & $(1 / 289)$ & $(44 / 150)$ & $(60 / 235)$ \\
MARB & 38.5 & a 24.1 & 21.9 & 2.0 & 1.5 & 0.4 & 0.7 & 31.1 & a 25.9 \\
& $(106 / 275)$ & $(58 / 241)$ & $(43 / 196)$ & $(5 / 251)$ & $(4 / 266)$ & $(1 / 270)$ & $(2 / 275)$ & $(47 / 151)$ & $(61 / 235)$ \\
CONT & 42.5 & b 13.8 & 29.2 & 3.7 & 1.1 & 0.4 & 1.1 & 34.2 & b 14.9 \\
& $(117 / 275)$ & $(32 / 232)$ & $(38 / 130)$ & $(10 / 267)$ & $(3 / 274)$ & $(1 / 270)$ & $(3 / 274)$ & $(41 / 120)$ & $(35 / 234)$ \\
\hline
\end{tabular}

( ${ }^{\mathrm{a}-\mathrm{b}}$ Means with different superscripts in each column indicates significant difference $\left.(P<0.05)\right)$

Table2: Results of multivariate regression analysis of odds for acquiring new S.aureus IMI in uninfected and infected with different pathogen between dry period and 7 \pm 3 DIM

\begin{tabular}{|c|c|c|c|c|c|c|c|c|c|}
\hline \multicolumn{2}{|c|}{ Variable } & \multirow[t]{2}{*}{ B } & \multirow[t]{2}{*}{ S.E } & \multirow[t]{2}{*}{ Wald } & \multirow[t]{2}{*}{$\mathrm{df}$} & \multirow[t]{2}{*}{ Sig. } & \multirow[t]{2}{*}{$\operatorname{Exp}(B)$} & \multicolumn{2}{|c|}{ 95\% CI $\operatorname{Exp}(B)$} \\
\hline & & & & & & & & lower & upper \\
\hline \multirow[t]{3}{*}{ treatment } & control & & & & & & & & \\
\hline & Tylosin & 0.618 & 0.270 & 5.228 & 1 & 0.022 & 1.855 & 1.092 & 3.150 \\
\hline & Marbofloxacin & 0.423 & 0.280 & 2.290 & 1 & 0.030 & 1.527 & 0.883 & 2.642 \\
\hline \multirow[t]{2}{*}{ Quarter position } & Front & & & & & & & & \\
\hline & Rear & 0.040 & 0.214 & 0.035 & 1 & 0.852 & 1.041 & 0.685 & 1.581 \\
\hline \multirow[t]{3}{*}{ Milk yield } & $>40 \mathrm{~kg}$ & & & & & & & & \\
\hline & $30-40 \mathrm{~kg}$ & 1.043 & 0.370 & 7.967 & 1 & 0.005 & 2.838 & 1.375 & 5.856 \\
\hline & $<30 \mathrm{~kg}$ & 1.689 & 0.364 & 21.539 & 1 & 0.000 & 5.416 & 2.654 & 11.055 \\
\hline \multirow[t]{2}{*}{ Parity } & 1 & & & & & & & & \\
\hline & $>2$ & 0.833 & 0.227 & 13.431 & 1 & 0.000 & 2.300 & 1.473 & 3.591 \\
\hline \multirow[t]{2}{*}{$\begin{array}{l}\text { Oxidant/antioxidant } \\
\text { marker }\end{array}$} & $\begin{array}{l}\text { DTNB }^{1} \\
\text { (pre-calving) }\end{array}$ & 0.068 & 0.100 & 0.456 & 1 & 0.500 & 1.070 & 0.879 & 1.302 \\
\hline & $\begin{array}{l}\text { FRAP }^{2} \\
\text { (pre-calving) }\end{array}$ & -0.33 & 0.243 & 1.890 & 1 & 0.169 & 0.716 & 0.444 & 1.153 \\
\hline Constant & & -3.15 & 0.508 & 38.489 & 1 & 0.000 & 0.043 & & \\
\hline
\end{tabular}

${ }^{1}$ DTNB: 5,5-dithiobis-2-nitrobenzoate 
${ }^{2}$ FRAP: ferric-reducing ability of plasma.

Table3: Results of cure rate for the different groups (Different letters $(a, b)$ above the numbers in each column indicates significant difference)

\begin{tabular}{|c|c|c|c|c|c|c|c|c|c|}
\hline Group & Total \%(n) & S.aureus & CNS & C.bovis & S.agalactea & Yeast & Other & Minor & Major \\
\hline \multirow[t]{3}{*}{ TYLO } & 72.3 & $74.0^{\mathrm{a}}$ & $62.5^{\mathrm{a}}$ & $100.0^{\mathrm{a}}$ & 100.0 & 100.0 & 100.0 & $71.0^{\mathrm{a}}$ & $75.9^{\mathrm{a}}$ \\
\hline & $(199 / 144)$ & $(50 / 37)$ & $(112 / 70)$ & $(30 / 30)$ & $(4 / 4)$ & $(1 / 1)$ & $(2 / 2)$ & $103 / 14)$ & $41 / 5)$ \\
\hline & & & & & & & & $(5$ & $(4$ \\
\hline \multirow[t]{3}{*}{ MARB } & 76.2 & $73.5^{\mathrm{a}}$ & $65.1^{\mathrm{a}}$ & $90.3^{a}$ & 100.0 & 100.0 & 100.0 & $75.3^{a}$ & $79.1^{\mathrm{a}}$ \\
\hline & $(185 / 141)$ & $(34 / 25)$ & $(106 / 73)$ & $(31 / 29)$ & $(9 / 9)$ & $(2 / 2)$ & $(3 / 3)$ & $107 / 14)$ & $34 / 4)$ \\
\hline & & & & & & & & $(2$ & (3 \\
\hline \multirow[t]{3}{*}{ CONT } & 59.6 & $58.1^{\mathrm{b}}$ & $52.8^{\mathrm{b}}$ & $76.7^{b}$ & 100.0 & 100.0 & 100.0 & $59.7^{\mathrm{b}}$ & $59.0^{\mathrm{b}}$ \\
\hline & $(233 / 139)$ & $(43 / 25)$ & $(140 / 74)$ & $(43 / 33)$ & $(1 / 1)$ & $(5 / 5)$ & $(1 / 1)$ & 113/18) & $26 / 4)$ \\
\hline & & & & & & & & (9 & $(4$ \\
\hline
\end{tabular}

( ${ }^{\mathrm{a}-\mathrm{b}}$ Means with different superscripts in each column indicates significant difference $\left.(P<0.05)\right)$

Table4: Results of final logistic regression model for the probability of cure of infected quarters during the dry period.

\begin{tabular}{|c|c|c|c|c|c|c|c|c|c|c|c|}
\hline \multirow[t]{2}{*}{ Variables } & & \multicolumn{2}{|c|}{ Total pathogens } & \multicolumn{2}{|c|}{ S.aureus } & \multicolumn{2}{|c|}{ CNS } & \multicolumn{2}{|c|}{ Minor } & \multicolumn{2}{|c|}{ Major } \\
\hline & & $\mathrm{P}$ & OR & $\mathrm{P}$ & OD & $\mathrm{P}$ & OD & $\mathrm{P}$ & OD & $\mathrm{P}$ & OD \\
\hline \multirow[t]{2}{*}{ Treatment } & Tylosin & 0.095 & 1.353 & 0.261 & 1.811 & 0.043 & 1.794 & 0.309 & 1.307 & 0.270 & 1.889 \\
\hline & Marbox & 0.096 & 1.427 & 0.190 & 1.905 & 0.045 & 1.811 & 0.47 & 1.722 & 0.380 & 1.298 \\
\hline Quarter position & Rear & 0.103 & -0.713 & 0.256 & 1.721 & 0.618 & 0.889 & 0.249 & 0.777 & 0.633 & 1.244 \\
\hline Parity & $>2$ & 0.127 & -0.721 & 0.249 & -1.865 & 0.644 & -1.121 & 0.377 & -1.219 & 0.189 & -1.990 \\
\hline \multirow[t]{2}{*}{ Milk yield } & $<30 \mathrm{~kg}$ & 0.003 & -0.426 & 0.011 & 0.207 & 0.887 & 0.951 & 0.673 & -1.144 & 0.000 & -0.126 \\
\hline & $30-40 \mathrm{~kg}$ & 0.174 & -0.695 & 0.728 & -0.793 & 0.944 & -0.976 & 0.658 & 1.146 & 0.242 & 0.474 \\
\hline $\mathrm{LS}^{1}$ at Drying off & $\geq 5$ & 0.07 & -1.12 & 0.076 & -1.31 & 0.041 & -1.22 & 0.042 & -1.299 & 0.079 & -1.344 \\
\hline $\mathrm{DTNB}^{2}$ & & 0.230 & 1.126 & 0.414 & 1.216 & 0.209 & 1.158 & 0.085 & 1.203 & 0.378 & 1.231 \\
\hline FRAP 3 & & 0.094 & 1.321 & 0.095 & 1.336 & 0.339 & 0.980 & 0.261 & 0.897 & 0.096 & 1.289 \\
\hline Constant & & 0.147 & 0.574 & 0.419 & 0.440 & 0.653 & 0.821 & 0.367 & 0.691 & 0.936 & 0.924 \\
\hline
\end{tabular}

${ }^{1} \mathrm{LS}$ : linear score 
${ }^{2}$ DTNB: 5,5-dithiobis-2-nitrobenzoate

${ }^{3}$ FRAP: ferric-reducing ability of plasma.

Table5: median (max-min) concentrations of DTNB and FRAP as oxidant and antioxidant markers in quarters within the groups of study considering total pathogen and $S$. aureus IMI. (DTNB1 and FRAP1: dry off, DTNB2 and FRAP2: post-calving).

\begin{tabular}{|c|c|c|c|c|c|c|c|}
\hline \multirow[b]{2}{*}{ Markers } & \multirow{2}{*}{$\begin{array}{l}\text { Quarter } \\
\text { Condition }\end{array}$} & \multicolumn{2}{|c|}{ TYLO } & \multicolumn{2}{|c|}{ MARB } & \multicolumn{2}{|c|}{ CONT } \\
\hline & & $\begin{array}{c}\text { Total } \\
\text { pathogen }\end{array}$ & S. aureus & $\begin{array}{c}\text { Total } \\
\text { pathogen }\end{array}$ & S. aureus & $\begin{array}{c}\text { Total } \\
\text { pathogen }\end{array}$ & S. aureus \\
\hline \multirow{4}{*}{$\begin{array}{l}\text { DTNB2 } \\
\mu \mathrm{mol} / \mathrm{s}\end{array}$} & New & 3.11(0.22- & 3.97(1.01- & 2.31(0.56- & 3.11(0.63- & 4.73(3.11- & 4.65(2.88- \\
\hline & infected & $7.22)^{\mathrm{a}}$ & $7.22)^{\mathrm{a}}$ & $7.80)^{\mathrm{a}}$ & $7.8)^{\mathrm{a}}$ & $5.12)^{\mathrm{a}}$ & $5.1)^{\mathrm{a}}$ \\
\hline & Healthy & $1.21(0.34-$ & $1.2(0.34-$ & $1.55(0.37-$ & $1.7(0.37-$ & $2.40(1.23-$ & $2.8(1.23-$ \\
\hline & & $4.2)^{\mathrm{b}}$ & $5.78)^{b}$ & $4.5)^{\mathrm{b}}$ & $7.22)^{b}$ & $5.83)^{b}$ & $5.83)^{b}$ \\
\hline \multirow{4}{*}{$\begin{array}{l}\text { FRAP2 } \\
\mu \mathrm{mol} / \mathrm{L}\end{array}$} & New & $1.0(0.45-$ & $1.3(0.38-$ & 0.67(0.33- & 0.77(0.33- & $0.62(0.23-$ & $0.83(0.44-$ \\
\hline & infected & 2.71) & 2.71) & 2.65) & 2.6) & 2.33) & 1.37) \\
\hline & Healthy & 0.89(0.39- & $1.12(0.34-$ & $0.63(0.24-$ & $0.63(0.24-$ & $0.67(0.23-$ & $0.67(0.23-$ \\
\hline & & $2.05)$ & $4.25)$ & 2.11) & 2.1) & 4.03) & 4.03) \\
\hline \multirow{3}{*}{$\begin{array}{l}\text { DTNB1 } \\
\mu \mathrm{mol} / \mathrm{s}\end{array}$} & Uncured & $1.78(0.41-$ & 1.94(0.89- & $1.79(0.3-$ & $1.79(0.47-$ & $1.71(0.54-$ & $3.12(1.04-$ \\
\hline & & $5.34)$ & $3.87)$ & $5.7)$ & $5.7)$ & 5.26 & $5.01)^{\mathrm{a}}$ \\
\hline & Cured & $\begin{array}{c}1.44(0.4- \\
5.05)\end{array}$ & $\begin{array}{c}2.09(0.4- \\
5.95)\end{array}$ & $\begin{array}{c}1.61(0.35- \\
4.89)\end{array}$ & $\begin{array}{c}1.5(0.58- \\
3.98)\end{array}$ & $\begin{array}{c}1.45(0.4- \\
5.02)\end{array}$ & $\begin{array}{c}1.5(0.69- \\
2.45)^{\mathrm{b}}\end{array}$ \\
\hline \multirow{4}{*}{$\begin{array}{l}\text { FRAP1 } \\
\mu \mathrm{mol} / \mathrm{L}\end{array}$} & Uncured & $0.55(0.23-$ & $0.46(0.25-$ & $0.67(0.22-$ & $0.41(0.25-$ & $0.49(0.31-$ & $0.44(0.30-$ \\
\hline & & $1.38)^{\mathrm{a}}$ & $2.30)^{\mathrm{a}}$ & $3.11)^{\mathrm{a}}$ & $2.5)^{\mathrm{a}}$ & $1.34)^{\mathrm{a}}$ & $0.74)^{\mathrm{a}}$ \\
\hline & Cured & 0.87 (0.33- & $0.9(0.34-$ & $1.12(0.45-$ & $1.05(0.4-$ & $0.87(0.23-$ & 1.03 (0.55- \\
\hline & & $1.32)^{b}$ & $3.07)^{b}$ & $1.8)^{b}$ & $2.01)^{b}$ & $1.66)^{b}$ & $2.06)^{b}$ \\
\hline
\end{tabular}

( ${ }^{\mathrm{a}-\mathrm{b}}$ Medians with different superscripts in each column indicates significant difference $(P<0.05)$ )

FRAP: ferric-reducing ability of plasma, DTNB: 5,5-dithiobis-2-nitrobenzoate.

Table6: Antimicrobial resistance of the four predominant RAPD types (A,B,E and G) in herd 1 and herd 2. 


\begin{tabular}{lcccccccc}
\hline & \multicolumn{7}{c}{ No of isolates of indicated RAPD type } \\
\hline \multirow{2}{*}{ Antimicrobials } & \multicolumn{2}{c}{ A } & \multicolumn{2}{c}{ B } & \multicolumn{2}{c}{ E } & \multicolumn{2}{c}{ G } \\
\cline { 2 - 9 } & Herd 1 & Herd 2 & Herd 1 & Herd 2 & Herd 1 & Herd 2 & Herd 1 & Herd 2 \\
\hline Marbofloxacin & $4 / 12$ & $1 / 5$ & $4 / 15$ & $1 / 5$ & $2 / 11$ & $1 / 7$ & $2 / 8$ & $0 / 4$ \\
& $33 \%$ & $20 \%$ & $27 \%$ & $20 \%$ & $18 \%$ & $14 \%$ & $25 \%$ & $0.0 \%$ \\
\cline { 1 - 9 } Tylosin & $10 / 12$ & $3 / 5$ & $9 / 15$ & $3 / 5$ & $5 / 11$ & $1 / 7$ & $1 / 8$ & $0 / 4$ \\
& $83 \%$ & $60 \%$ & $60 \%$ & $60 \%$ & $45 \%$ & $14 \%$ & $12.5 \%$ & $0.0 \%$ \\
Penicillin & $7 / 12$ & $4 / 5$ & $7 / 15$ & $3 / 5$ & $5 / 11$ & $2 / 7$ & $2 / 8$ & $1 / 4$ \\
& $58 \%$ & $80 \%$ & $47 \%$ & $60 \%$ & $45 \%$ & $29 \%$ & $25 \%$ & $25 \%$ \\
Cloxacillin & $6 / 12$ & $3 / 5$ & $8 / 15$ & $1 / 5$ & $2 / 11$ & $1 / 7$ & $0 / 8$ & $0 / 4$ \\
\cline { 3 - 9 } Kanamycin & $50 \%$ & $60 \%$ & $53 \%$ & $20 \%$ & $18 \%$ & $14 \%$ & $0.0 \%$ & $0.0 \%$ \\
& $2 / 12$ & $0 / 5$ & $2 / 15$ & $0 / 5$ & $1 / 11$ & $0 / 7$ & $0 / 8$ & $0 / 4$ \\
& $17 \%$ & $0.0 \%$ & $13 \%$ & $0.0 \%$ & $9 \%$ & $0.0 \%$ & $0.0 \%$ & $0.0 \%$ \\
\hline
\end{tabular}

Figures

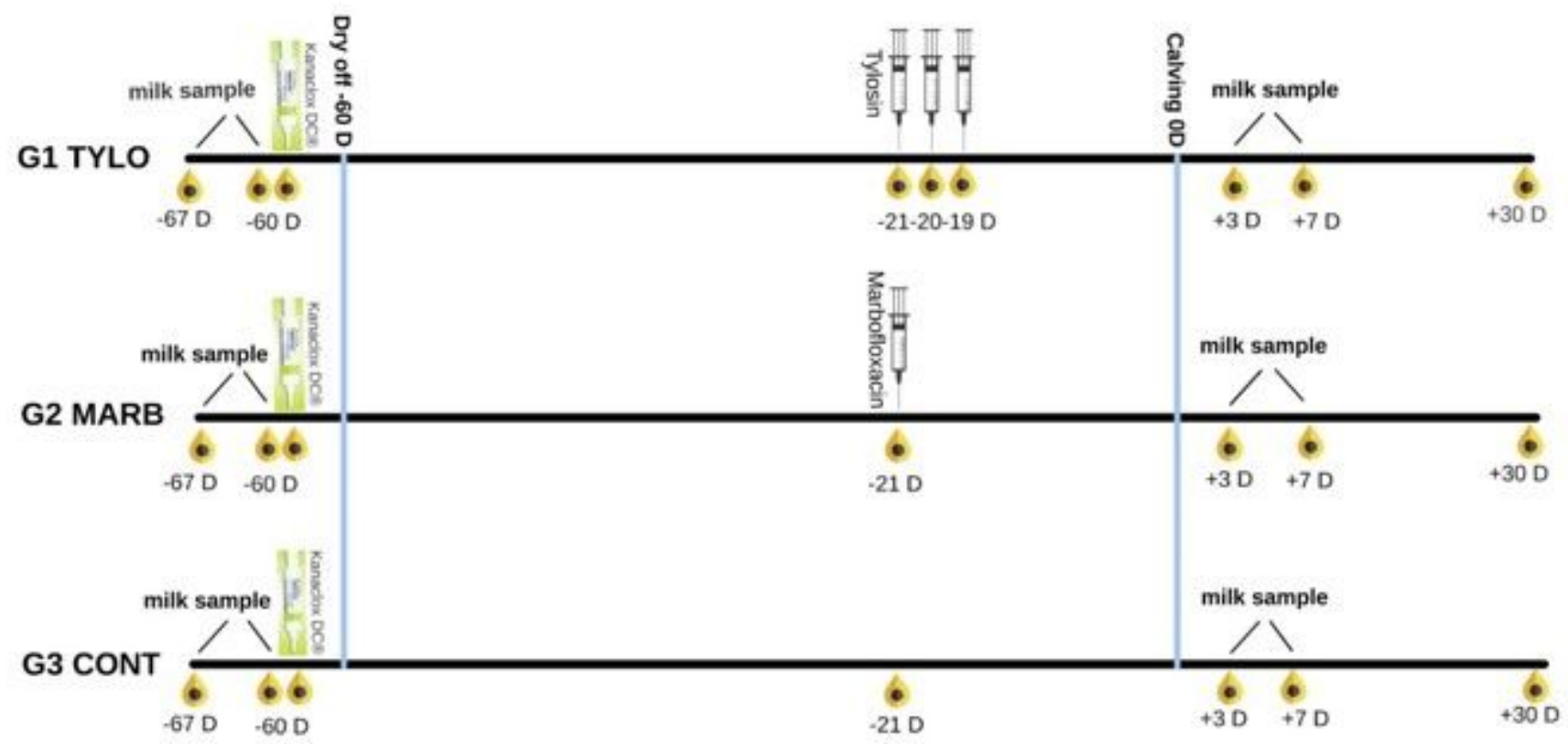

Figure1: schematic design of study

Figure 1 
schematic design of study

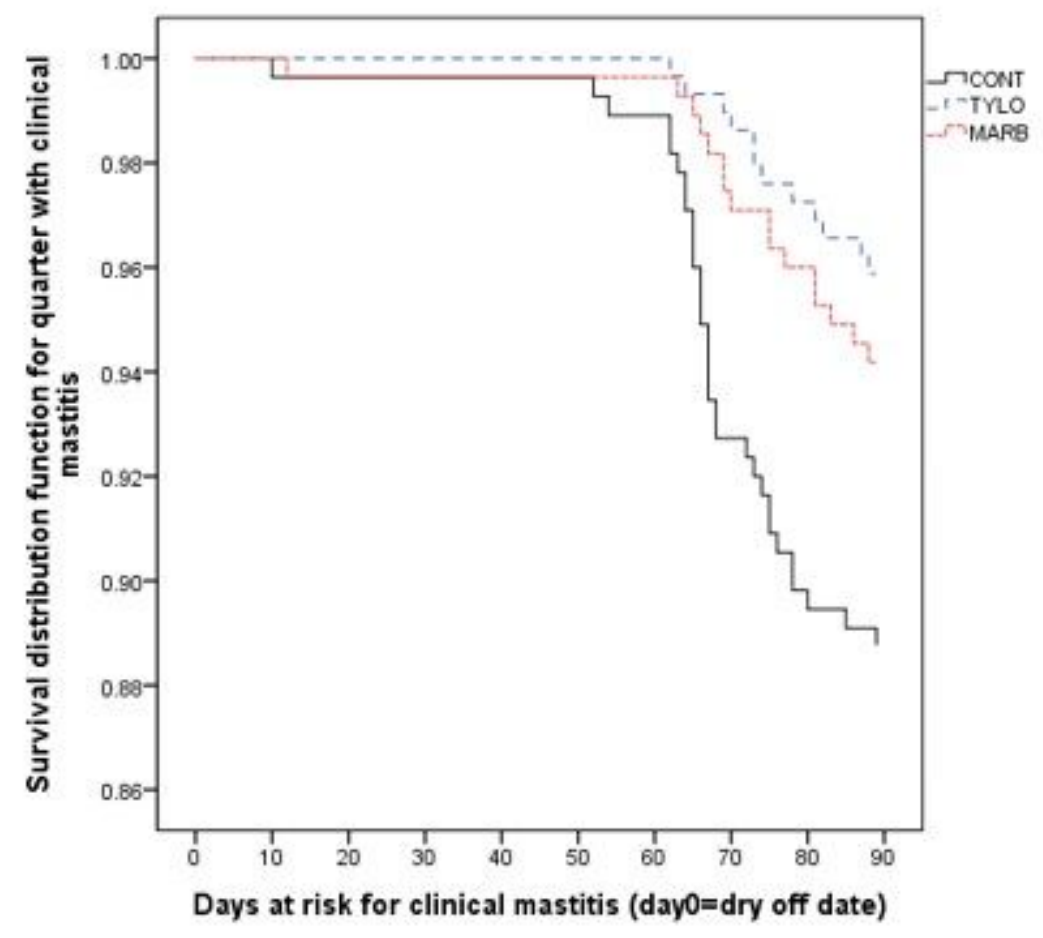

Figure 2

Kaplan-Meier survival curves providing survival distribution function of quarter with clinical mastitis for each of the treatment groups from drying off (day 0) until DIM 30 (day 90).

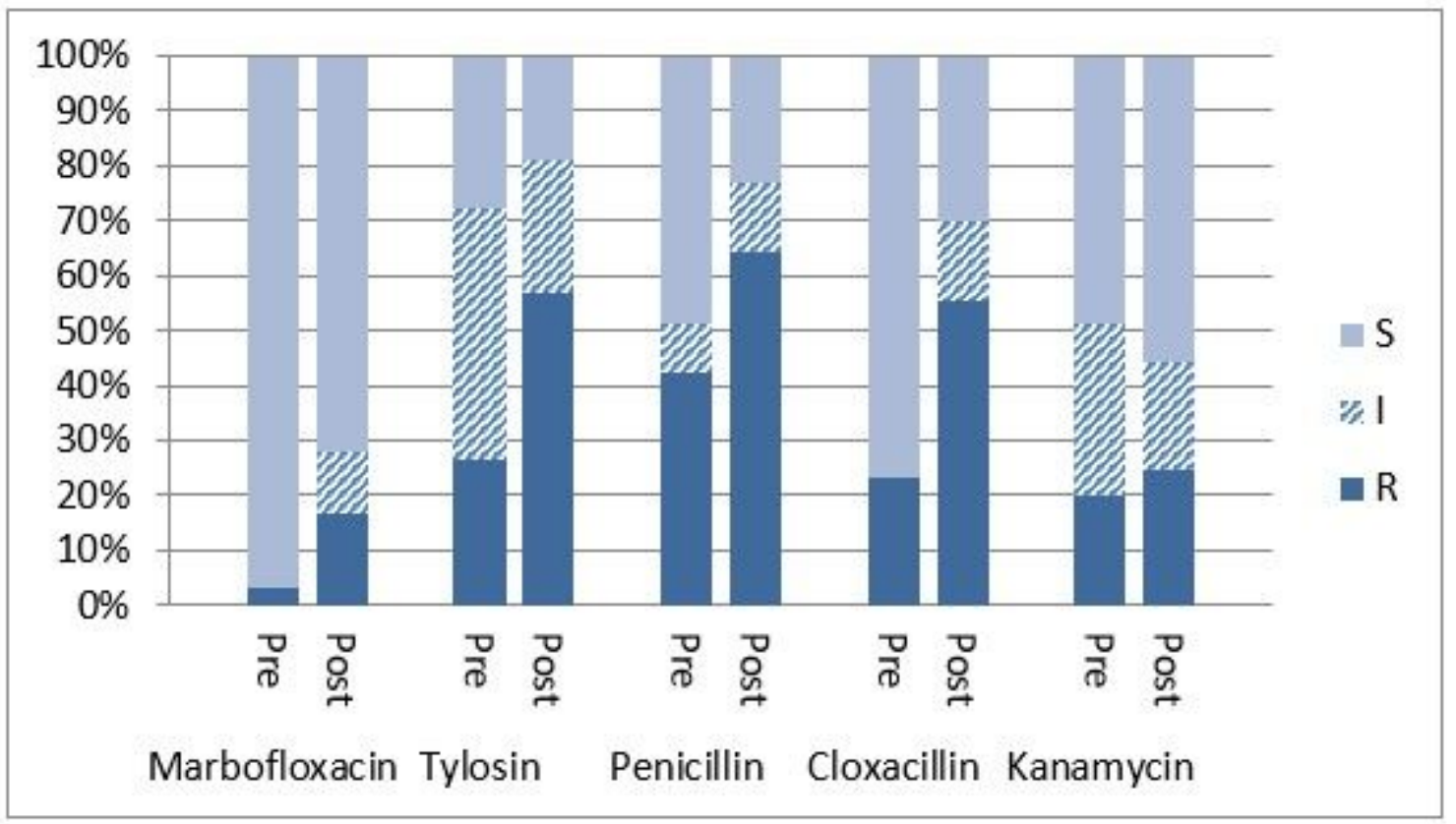

Figure 3 
Antimicrobial susceptibility test results of 5 antimicrobial agents used as intra-mammary infusion or systemic injection. (S: susceptible, I: intermediate and R: resistant response. Pre: dry off samples, Post: post calving samples).

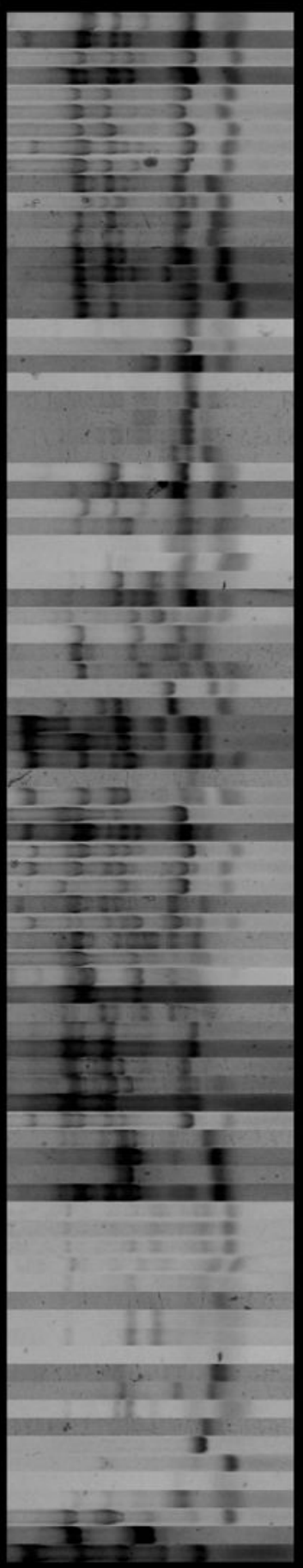

\section{Figure 4}

dendrogram of RAPD-PCR types of S. aureus isolates from dry off and 7 \pm 3 DIM. A: strains from dry off, B: strains from post-calving. $60 \%$ similarity was considered for classification of RAPD types. 


\section{Supplementary Files}

This is a list of supplementary files associated with this preprint. Click to download.

- answerstochecklist2.docx

- NC3RsARRIVEGuidelinesChecklist.docx 